\title{
Aspek Pajak Penghasilan Final Pada Sektor Usaha Mikro Kecil dan Menengah (Studi Kasus PT PCT Tangerang)
}

\author{
Badar Murifal \\ Universitas Bina Sarana Informatika \\ badar.bml@bsi.ac.id
}
Murifal, B. (2019). Aspek Pajak Penghasilan Final Pada Sektor Usaha Mikro Kecil dan Menengah (Studi Kasus PT PCT Tangerang). Moneter, 6(1), 33-38.

\begin{abstract}
Indonesia cut the final income tax rate for small and medium-sized enterprises by half, to 0.5 percent of their annual sales, in a move to help businesses manage their cash flow and expansion. While the current arrangement only demands simple accounting, small and medium-sized enterprises say it also means they have to pay income tax when they are at loss, which disrupts their cash flow(Jakarta Globes, 2018). The Government has shown its strong support for the development of small and medium enterprises (SMEs). After improving the tax facility for venture capital companies who invest in SMEs, the Government has now issued Government Regulation (GR) No.23/2018 (GR-23) which stipulates a new "final tax"rate for SMEs. GR-23 will enter into force on 1 July 2018 and revokes GR No.46/2013 regarding final tax on taxpayers within a certain turnover. The final tax regime, introduced in GR-46, is applicable for taxpay ers with annual gross turnover of not more than IDR 4.8 billion (approximately USD 340 thousand), excluding the following income: a.fees from the delivery of certain freelance services by individuals; $b$. overseas income which has been taxed in the source country; $c$. income also subject to final tax; and d. non - taxable income. The threshold of IDR 4.8 billion per annum is based on the previous years' activity, including gross turnover sourced from branches. If during a fiscal year the gross turnover exceeds IDR 4.8 billion, the taxpayer remains subject to final tax for the current year but must adopt the " normal tax " rate (Article 17 or Article 31E Income Tax) for the following year. While the provisions on gross turnover generally remain unchanged, GR - 23 now reduces the final tax rate to $0.5 \%$ from the previous $1 \%$.
\end{abstract}

Key words : Final Income Tax, Micro, Small and Medium Enterprises.

\section{PENDAHULUAN}

Pajak menjadi penerimaan negara terbesar yang digunakan negara untuk membangun seluruh daerah atau wilayah yang ada di Indonesia. Untuk itu diperlukan partisipasi warga negara dengan patuh membayar pajak.

Setiap orang pastinya sudah mengenal pajak, apalagi para pengusaha. Sampai-sampai mereka harus berkonsultasi kepada ahli pajak (konsultan pajak) agar mereka dapat membayarkan ketentuan pajak dari bisnisnya. Namun apakah mereka memahami tentang apa itu fungsi sebenarnya dari pajak? Dan sepertinya masyarakat bahkan para pelaku bisnis sekalipun masih banyak yang belum memahami sepenuhnya tentang apa saja fungsi dari pajak.

Pajak sendiri berupa pungutan wajib yang harus dibayarkan oleh seseorang dan badan usaha bagi kepentingan Negara dan akan digunakan lagi untuk kepentingan masyarakat umum. Dana yang diperoleh dari pembayaran pajak, akan digunakan oleh pemerintah untuk membangun berbagai fasilitas umum, melakukan pembangunan jalan dan masih banyak lagi yang lainnya, yang mana untuk pemungutan pajak itu sendiri telah diatur berdasarkan undang-undang.
Sama halnya dengan yang lain, pajak juga memiliki beberapa kriteria yang seharusnya Anda ketahui. Sebagai warga Negara bahkan para pengusaha harus mengerti tentang apa saja setiap masing-masing kriterianya.Jika anda mendirikan Usaha Kecil Menengah (UKM) atau Usaha Mikro Kecil Menengah(UMKM) , maka kini Anda sudah berkewajiban membayar pajak. Lantas apa saja Pajak UKM/UMKM, berapa nilai yang harus dibayarkan, dan bagaimana cara membayarnya?

Pajak ialah iuran rakyat kepada negaranya berdasarkan Undang-Undang atau peralihan kekayaan dari sektor swasta kepada sektor publik yang bisa dipaksakan dan yang langsung dapat ditunjuk serta digunakan untuk membiayai kebutuhan atau kepentingan umum (Rochmat Soemitro, 2012)
1. Kriteria pajak
a. Kontribusi wajib bagi setiap warganegara
b. Bersifat memaksa
c. Warganegara tidak mendapat kontra prestasi.
d. Berdasarkan undang-undang yang berlaku.

\section{Manfaat pajak bagi suatu negara}

Banyaknya masyarakat yang belum taat membayar pajak disebabkan minimnya informasi masyarakat mengenai manfaat pajak. Pajak sangat bermanfaat bagi negara. Secara lengkap pajak banyak digunakan untuk : 
a. Membiayai pengeluaran-pengeluaran negara, seperti: pengeluaran yang bersifat self liquiditing, contohnya: pengeluaran untuk proyek produktif barang ekspor.

b. Membiayai pengeluaran reproduktif, seperti: pengeluaran yang memberikan keuntungan ekonomis bagi masyarakat, contohnya: pengeluaran untuk pengairan dan pertanian.

c. Membiayai pengeluaran yang bersifat tidak self liquiditing dan tidak reproduktif, contohnya: pengeluaran untuk pendirian monumen dan objek rekreasi.

d. Membiayai pengeluaran yang tidak produktif, contohnya: pengeluaran untuk membiayai pertahanan negara atau perang dan pengeluaran untuk penghematan di masa yang akan datang yaitu pengeluaran untuk anak yatim piatu.

Jadi dengan taat membayar pajak masyarakat akan mendapatkan manfaat:

a. Fasilitas umum dan infrastruktur, seperti: jalan, jembatan, sekolah, rumah sakit

b. Pertahanan dan keamanan, seperti: bangunan, senjata, perumahan hingga gaji-gajinya

c. Subsidi pangan dan Bahan Bakar Minyak

d. Kelestarian Lingkungan hidup dan Budaya

e. Dana Pemilu

f. Pengembangan Alat transportasi Massa, dan lainlainnya.

Pajak yang telah disetorkan masyarakat akan digunakan negara untuk kesejahteraan masyarakat, antara lain: memberi subsidi barang-barang yang dibutuhkan masyarakat dan membayar utang-utang negara. Selain itu pajak juga digunakan untuk menunjang Usaha Mikro, Kecil, dan Menengah agar perekonomian dapat terus berkembang.

3. Jenis pajak di Indonesia (Diana, A \& Setiawati, L : 2014)

a. Pajak Penghasilan ( $\mathrm{PPh})$

b. Pajak Pertambahan Nilai ( PPN)

c. Pajak Penjualan ats Barang Mewah ( PPnBM)

d. Bea Meterai

e. Pajak Bumi dan Bangunan ( PBB)(Anastasia Diana \& Lilis Setiawati, 2014)

\section{Pajak Penghasilan ( PPh) Final}

Berdasarkan ketentuan yang berlaku, penghasilan terbagi menjadi dua; penghasilan yang merupakan objek pajak dan penghasilan yang bukan objek pajak. Begitu pula cara pengenaan pajak penghasilan (PPh) atas penghasilan yang merupakan objek pajak, juga terbagi menjadi dua. Pertama, dikenakan PPh secara umum dengan menggunakan tarif pasal 17 (tarif umum), dan pengenaannya dilakukan di SPT Tahunan. Kedua, dikenakan PPh Final. Pengenaan $\mathrm{PPh}$ secara final berarti penghasilan yang diterima atau diperoleh akan dikenakan $\mathrm{PPh}$ dengan tarif tertentu, dan dasar pengenaan pajak tertentu pada saat penghasilan tersebut diterima atau diperoleh. $\mathrm{PPh}$ yang dikenakan, baik yang dipotong pihak lain maupun yang disetor sendiri, bukan merupakan pembayaran di muka atas $\mathrm{PPh}$ terutang, tetapi sudah langsung melunasi $\mathrm{PPh}$ terutang untuk penghasilan tersebut (Mardiasmo, 2011)

Penghasilan yang dikenakan $\mathrm{PPh}$ Final ini tidak akan dihitung lagi PPh nya di SPT Tahunan untuk dikenakan tarif umum bersama-sama dengan penghasilan lainnya. Begitu juga, PPh yang sudah dipotong atau dibayar tersebut juga bukan merupakan kredit pajak di SPT Tahunan. PPh Final menurut Peraturan Pemerintah Republik Indonesia Nomor 46 Tahun 2013 dikenakan pada wajib pajak pribadi dan badan yang memiliki omzet usaha kurang dari Rp 4,8 miliar dalam setahun.

Pajak yang Anda bayarkan digunakan untuk kepentingan bersama dan manfaatnya dapat dirasakan bersama, yaitu :

a. Mematuhi Peraturan

Berdasarkan Pasal 4 ayat (2) Undang-undang Pajak Penghasilan, Undang-undang memberikan mandat kepada Pemerintah untuk mengenakan PPh Final atas penghasilan-penghasilan tertentu. Berdasarkan ketentuan ini Pemerintah mengeluarkan Peraturan Pemerintah untuk mengenakan PPh Final atas penghasilan tertentu dengan pertimbangan kesederhanaan, kemudahan, serta pengawasan.Pengenaan $\mathrm{PPh}$ Final sebagian berasal dari ketentuan Pasal 4 ayat (2) ini. Namun demikian, ada juga pengenaan $\mathrm{PPh}$ final berdasarkan Pasal lain yaitu Pasal 15, Pasal 19, Pasal 21, Pasal 22, Pasal 23 dan Pasal 26 Undang-undang $\mathrm{PPh}$.

b. Ikut Membangun Indonesia

Salah satu fungsi pajak adalah untuk pembangunan infrastruktur. Infrastruktur transportasi seperti jalan dan jembatan dibangun membangun dana dari pajak. Selain itu, dana dari pemungutan pajak juga digunakan untuk meningkatkan fasilitas kesehatan serta memberikan subsidi di bidang pertanian. Jika Anda juga belum tahu, pajak merupakan salah satu anggaran terbesar dalam Anggaran Pendapatan dan Belanja Negara dan sangat berpengaruh bagi kemajuan pendidikan di Tanah Air karena hasil penarikan pajak juga digunakan untuk membiayai Biaya Operasional Sekolah. Sebagai warga negara sekaligus wajib pajak teladan, mari jadikan Indonesia lebih baik lagi melalui pengumpulan pajak. Pajak $1 \%$ dari penjualan Anda sangat berarti bagi kemajuan bangsa.

c. Menghindari Risiko Bisnis

Direktorat Jenderal Pajak akan memeriksa laporan pajak usaha atau bisnis Anda. Jika Anda lalai dalam melakukan setor dan lapor pajak, DJP bakal menutup bisnis yang telah Anda bangun 
selama ini. Hindari risiko bisnis terjadinya permasalahan tersebut dari sekarang.

\section{Pengertian UMKM.}

Usaha Kecil dan Menengah disingkat UKM adalah sebuah istilah yang mengacu ke jenis usaha kecil yang memiliki kekayaan bersih paling banyak Rp 200 juta tidak termasuk tanah dan bangunan tempat usaha. Dan usaha yang berdiri sendiri.

Pengertian Usaha Kecil adalah: "Kegiatan ekonomi rakyat yang berskala kecil dengan bidang usaha yang secara mayoritas merupakan kegiatan usaha kecil dan perlu dilindungi untuk mencegah dari persaingan usaha yang tidak sehat."(K. P. RI, 1998)

\section{Peraturan Pemerintah (PP) Nomor 23 Tahun 2018}

Pelaku usaha mikro, kecil, dan menengah (UMKM) beromzet maksimal Rp4,8 miliar setahun bisa bernapas lega atas penurunan tarif Pajak Penghasilan $(\mathrm{PPh})$ Final dari $1 \%$ menjadi 0,5\%. .Dengan kebijakan ini, diharapkan makin banyak UMKM masuk dalam basis wajib pajak dan berkontribusi pada perekonomian nasional.(Universitas Brawijaya, 2018). Tarif baru pajak UMKM ini tertuang dalam Peraturan Pemerintah (PP) Nomor 23 Tahun 2018 tentang Pajak Penghasilan atas Penghasilan Dari Usaha yang Diterima atau Diperoleh Wajib Pajak yang memiliki Peredaran Bruto Tertentu. PP tersebut menggantikan PP sebelumnya Nomor 46 Tahun 2013(K. K. RI, 2018). Sementara aturan turunannya dalam bentuk Peraturan Menteri Keuangan (PMK) mengenai pajak UMKM, dijanjikan akan segera terbit. Sejak 1 Juli 2018, Pemerintah memangkas tarif $\mathrm{PPh}$ Final dari 1\% menjadi 0,5\% dengan tujuan membantu bisnis UMKM terus berkembang, menjaga aliran keuangannya (cash flow) sehingga dapat digunakan untuk tambahan modal usaha. Dengan begitu, membayar pajak tidak lagi dianggap sebagai beban dan momok.

Namanya diskon, tidak semua UMKM bisa menikmatinya. Tarif pajak setengah persen hanya berlaku untuk:

a. UMKM yang memiliki peredaran bruto (omzet) tidak melebihi Rp4,8 miliar dalam satu tahun pajak. Antara lain usaha dagang, industri jasa seperti toko/kios/los kelontong, pakaian, elektronik, bengkel, penjahit, warung atau rumah makan, salon, dan usaha lainnya

b. Berlaku untuk UMKM konvensional atau offline maupun yang berjualan di toko online (marketplace dan media sosial).

Penggunaan tarif istimewa ini pun ada batas waktunya, sesuai dengan PP Nomor 23 Tahun 2018, antara lain:

a. Bagi Wajib Pajak Orang Pribadi selama 7 tahun. b. Wajib Pajak Badan berbentuk Koperasi, Persekutuan Komanditer atau Firma selama 4 tahun.

c. Wajib Pajak Badan berbentuk Perseroan Terbatas (PT) selama 3 tahun.

Saat batas waktu tersebut ditutup, UMKM yang dijalankan Wajib Pajak Orang Pribadi, Wajib Pajak Badan, dan Wajib Pajak PT tidak bisa lagi menikmati tarif rendah ini. Mereka harus menyelenggarakan pembukuan atau menyusun laporan keuangan dengan rapi, serta membayar pajak penghasilan berdasarkan tarif umum sesuai Undang-undang PPh.

Tidak ada alasan lagi tidak bisa membuat pembukuan, karena periode waktu yang diberikan sudah cukup bagi UMKM untuk belajar menyusun laporan keuangan. Apalagi di era digital sekarang ini, bikin pembukuan sudah lebih mudah. Tinggal berselancar di dunia maya, keluarlah cara maupun aplikasi pembukuan sederhana yang bisa ditiru. Bisa juga belajar dari bimbingan Account Representative Ditjen Pajak.

\section{Perbedaan PP 46 Tahun 2013 dengan PP 23 Tahun 2018.(Kawan Pajak.com, 2018)}

Tabel 1.

Perbedaan PP 46 Tahun 2013 dengan PP 23 Tahun 2018

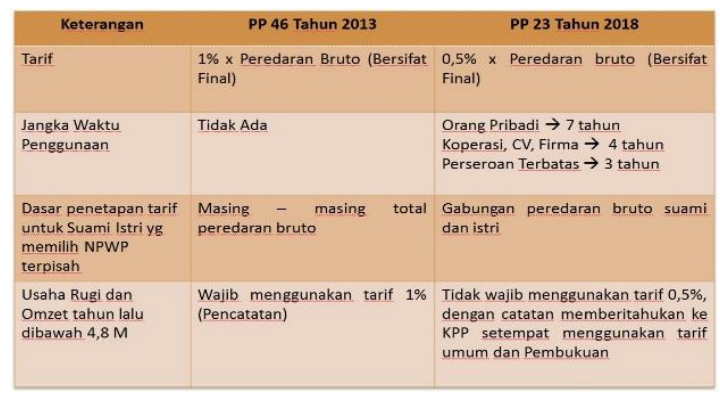

Sumber:

https://www.kawanpajak.com/2018/08/perbandingan-pp$\underline{46-v s-p p-23 . h t m l}$

Tabel 2.

Perbedaan PP 46 Tahun 2013 dengan PP 23 Tahun 2018

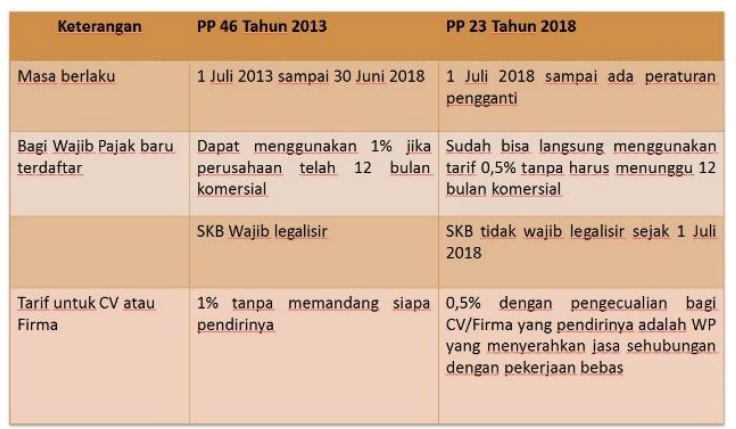

Sumber:

https://www.kawanpajak.com/2018/08/perbandingan-pp46-vs-pp-23.html 


\section{Dampak penurunan PPH Final UMKM dari} $1 \%$ menjadi $0,5 \%$

a. Investasi Pemerintah Jangka Menengah-Panjang dan menambah basis perpajakan.

b. Mendorong UMKM untuk naik kelas ke industri yang lebih besar.

c. Meningkatkan kontribusi UMKM terhadap Produk Domestik Bruto ( PDB).

d. Grace period menutup celah penghindaraan pajak-skenario pelaku UMKM "abadi “ dengan memecah usaha.

e. Mendorong UMKM untuk lebih berorientasi ekspor.

f. Meningkatkan penyerapan tenaga kerja di sektor UMKM.

g. Memberikan insentif tambahan bagi UMKM dan kepastian berusaha.

h. Mendorong lahirnya UMKM baru dan pengembangan UMKM.

\section{Keuntungan PPh Final UMKM}

Aturan penurunan tarif pajak menjadi $0,5 \%$ sangat bermanfaat bagi pelaku UMKM. Beberapa keuntungan itu, di antaranya:

a. UMKM dapat membayar pajak dengan mudah dan sederhana. Karena PPh Final, maka perhitungan pajak buat UMKM offline maupun online tinggal menjumlahkan peredaran bruto dalam sebulan, kemudikan dikalikan tarif. Simpel kan

b. Bisa mengurangi beban pajak para pelaku UMKM. Dengan tarif murah, sisa omzet bersih setelah dipotong pajak bisa dipakai pengusaha untuk mengembangkan usahanya

c. Tarif pajak yang rendah dapat merangsang orang untuk terjun sebagai wirausaha. Jadi tidak perlu khawatir dibebankan pajak tinggi

d. Dengan tarif istimewa itu diharapkan mendorong kepatuhan UMKM dalam membayar pajak serta meningkatkan basis wajib pajak

e. UMKM bisa naik kelas. Karena setelah mereka dapat menyusun laporan keuangan secara rapi, patuh membayar pajak, dapat menjadi jalan bagi mereka untuk memperoleh akses permodalan lewat bank .

Pemerintah telah memutuskan untuk meringankan tarif $\mathrm{PPh}$ Final menjadi 0,5\%. Namun, ketentuan ini bersifat opsional karena wajib pajak dapat memilih untuk mengikuti tarif dengan skema final $0,5 \%$, atau menggunakan skema normal yang mengacu pada pasal 17 Undang-Undang Nomor 36 Tahun 2008 tentang Pajak Penghasilan.

Sifat opsional ini memberi keuntungan bagi wajib pajak karena:

a. Bagi wajib pajak (WP) pribadi dan badan yang belum dapat menyelenggarakan pembukuan dengan tertib, penerapan PPh Final 0,5\% memberikan kemudahan bagi mereka untuk melaksanakan kewajiban perpajakan. Sebab, perhitungan pajak menjadi sederhana yakni $0,5 \%$ dari peredaran bruto/omzet. Namun, penerapan PPh Final memiliki konsekuensi yakni WP tetap harus membayar pajak meski sedang dalam keadaan rugi.

b. Sementara, WP badan yang telah melakukan pembukuan dengan baik dapat memilih untuk dikenai Pajak Penghasilan berdasarkan tarif normal yang diatur pasal 17 UU No. 36 tentang Pajak Penghasilan. Konsekuensinya, perhitungan tarif $\mathrm{PPh}$ akan mengacu pada lapisan penghasilan kena pajak. Selain itu, WP juga terbebas dari PPh bila mengalami kerugian fiskal.

Menghitung pajak UMKM sangat mudah, tinggal menjumlahkan omzet dalam sebulan, lalu dikalikan tarif $0,5 \%$. Wajib dibayarkan tanggal 15 setiap bulan berikutnya. Karena baru efektif berlaku 1 Juli 2018, maka Wajib Pajak dengan omzet sampai Juni yang disetorkan Juli masih dihitung tarif $1 \%$. Sementara untuk omzet Juli yang pajaknya disetorkan pada Agustus sudah menggunakan tarif 0,5\% dikali omzet Juli. Begitupula dengan Wajib Pajak UMKM yang baru mendaftar Juli 2018, dan setelahnya bisa langsung kena tarif $0,5 \%$ untuk omzetnya. Penyesuaian tarif secara otomatisasi tanpa persetujuan, pemberitahuan atau surat apapun dari Kantor Pelayanan Pajak (KPP).

\section{METODE PENELITIAN}

Metode penelitian yang dipakai adalah metode penelitian kualitatif yang berlandaskan pada paradigma interpretatif dan konstruktif, yang memandang realitas sosial sebagai sesuatu yang holistik atau utuh, kompleks, dinamis, penuh makna dan hubungan gejala bersifat interaktif dan digunakan untuk meneliti pada kondisi obyek yang alamiah, bukan eksperimen, dimana peneliti sebagai instrumen kunci, teknik pengumpulan data dilakukan secara triangulasi (gabungan), analisis data bersifat induktif. Penelitian ini menggunakan metode kualitatif karena peneliti ingin mengetahui dan menganalisis secara mendalam tentang aspek pajak penghasilan pada UMKM di Indonesia.

\section{Data dan Sumber Data}

Data sekunder adalah data yang diperoleh dalam bentuk data yang sudah jadi, data ini diperoleh dari dokumen-dokumen terkait misalnya artikel, buku, on line website provider.

\section{Teknik Analisis Data}

Teknik analisis data yang digunakan dalam penelitian ini adalah model interaktif dengan melalui tiga prosedur, yaitu:

a. Reduksi data

Merupakan proses penilaian, pemusatan, perhatian dan penyederhanaan, pengabstrakan dan transformasi data yang muncul dari catatan tertulis dilapangan. Teknik analisis ini diperlukan peneliti 
agar mengarahkan dan menajamkan analisis dengan menggolongkanya dan membuang yang tidak

b. Penyajian data.

Informasi yang tersusun dan memberikan kemungkinan tentang adanya penarikan kesimpulan dan mengambil tindakan. Bentuknya dapat diikuti gambaran atau skema dari beberapa tabel yang di rancang untuk menyusun agar dapat di mengerti. Teknik analisis ini diperlukan oleh peneliti untuk memudahkan peneliti dalam melihat gambaran secara umum tentang apa yang sedang terjadi atau hasil data yang diperoleh selama penelitian sehingga dapat ditentukan apa yang selanjutnya harus dilakukan oleh peneliti.

c. Menarik kesimpulan.

Data-data yang telah dikumpulkan dan dianalisis tersebut dapat di tarik kesimpulan-kesimpulan. Penarikan kesimpulan dilakukan selama penelitian berlangsung. Teknik analisis data dengan menarik kesimpulan ini peneliti akan memberikan kesimpulan dari hasil analisis data yang telah dilakukan serta memberikan saran-saran sebagai rekomendasi lanjutan untuk kebijakan-kebijakan yang akan diambil pelaku usaha dibisnis UMKM.

Alasan pemilihan teknik analisis data menggunakan model interaktif yaitu karena model tersebut akan memudahkan peneliti. Data-data yang telah diperoleh, diseleksi terlebih dahulu, setelah itu disajikan dalam laporan penelitian dengan memberikan analisa-analisa sebelum dilakukan langkah yang terakhir yaitu menarik kesimpulan.

\section{HASIL DAN PEMBAHASAN}

Dari penelitian yang dilakukan oleh penulis , pada laporan keuangan bulanan tahun pajak 2018 didapat data-data sebagai berikut :

Tabel 3. Data Laporan Laba Rugi, Penjualan dan Laba Setelah Pajak bulanan Tahun 2018

\begin{tabular}{|c|c|c|c|c|c|c|c|c|}
\hline Keteranga & Jan & Feb & Mar & Apr & Mei & Jun & Jul & $\mathrm{Ags}$ \\
\hline $\begin{array}{l}\text { Tarif } \\
\text { oriut }\end{array}$ & $1 \%$ & $1 \%$ & $1 \%$ & $1 \%$ & $1 \%$ & $1 \%$ & $0,5 \%$ & $0,5 \%$ \\
\hline $\begin{array}{l}\text { Penjualan } \\
\text { Penjula }\end{array}$ & 78.573 & 57.579 & 75.636 & 169.049 & 113.026 & 58.500 & 138.064 & 136.242 \\
\hline & 47.868 & 49.712 & $\begin{array}{l}59.490 \\
\end{array}$ & 81.743 & 85.519 & 65.523 & 85.615 & 78.291 \\
\hline $\begin{array}{l}\text { Laba } \\
\text { Kotor }\end{array}$ & 30.075 & 7.867 & 16.145 & 87.306 & 27.506 & -7.024 & 52.449 & 57.951 \\
\hline $\begin{array}{l}\text { Biaya } \\
\text { operasi }\end{array}$ & \begin{tabular}{|l|l|}
19.661 \\
\end{tabular} & 21.656 & $\begin{array}{l}18.463 \\
\end{array}$ & 25.087 & 28.240 & 24.704 & 21.563 & 20.680 \\
\hline $\begin{array}{l}\text { Laba } \\
\text { Operasi }\end{array}$ & $\begin{array}{ll}11.044 \\
\end{array}$ & $\begin{array}{l}(13.789) \\
\end{array}$ & $(2.318)$ & 62.218 & $\begin{array}{l}(734) \\
\end{array}$ & (31.728) & 30.885 & 37.271 \\
\hline $\begin{array}{l}\text { Pendapata } \\
\text { n \& b bayag } \\
\text { lain-lain }\end{array}$ & 0 & 500 & (719) & $\begin{array}{l}(1.366) \\
\end{array}$ & $\begin{array}{l}(2.437) \\
\end{array}$ & 0 & $\begin{array}{l}(2.437) \\
\end{array}$ & 0 \\
\hline 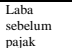 & $\begin{array}{l}11.044 \\
\end{array}$ & $\begin{array}{l}(14.289) \\
\end{array}$ & (1.599) & 63.584 & $\begin{array}{l}.703 \\
\end{array}$ & $(31.728)$ & 33.323 & 37.271 \\
\hline $\begin{array}{l}\text { Pajak } \\
\text { penghasila } \\
\text { n final }\end{array}$ & 785 & 576 & 756 & 1.690 & 1.130 & 585 & 690 & 681 \\
\hline $\begin{array}{l}\text { Laba } \\
\text { setelah } \\
\text { Pajak }\end{array}$ & 10.259 & $(14.865)$ & $(2.355)$ & 61.894 & 573 & $\begin{array}{l}(32.284) \\
\end{array}$ & 32.633 & 36.590 \\
\hline
\end{tabular}

Sumber : Hasil penelitian (2018)

Tabel 4. Data Pajak Penghasilan FINAL bulanan 2018

\begin{tabular}{|c|c|c|c|c|}
\hline No & Bulan & $\begin{array}{c}\text { PP 46, } \\
2013( \\
1 \%)\end{array}$ & $\begin{array}{l}\text { PP 23, } \\
2018( \\
0,5 \%)\end{array}$ & Total \\
\hline 1 & Jan 2018 & 785 & 0 & 785 \\
\hline 2 & Feb 2018 & 576 & 0 & 576 \\
\hline 3 & Mar 2018 & 756 & 0 & 756 \\
\hline
\end{tabular}

\begin{tabular}{rrrrr}
\hline 4 & Apr 2018 & 1.690 & 0 & 1.690 \\
\hline 5 & Mei 2018 & 1.130 & 0 & 1.130 \\
\hline 6 & Juni 2018 & 585 & 0 & 585 \\
\hline 7 & Juli 2018 & 0 & 690 & 690 \\
\hline 8 & Ags 2018 & 0 & 681 & 681 \\
\hline & TOTAL: & 5.522 & 1.371 & 6.893 \\
\hline
\end{tabular}

Sumber : Hasil penelitian (2018)

1. Jurnal akuntansi .

Db. PPh Final ( rek biaya) 6.893

Kr. Hutang pajak

\section{Cara membayar pajak UMKM}

a. Sebelumnya bisa buat kode biling di DJP Online (SSE1, SSE2, SSE3), layanan biling-djp/di KPP/KP2KP, Kring Pajak 1500200, petugas teller/customer service bank dan kantor pos, internet banking, ASP, SMS ID Biling *141*500\#, serta via ATM

b. Pembayaran pajak penghasilan bisa datang langsung ke kantor pos atau perbankan yang ditunjuk langsung Menteri Keuangan (Menkeu), internet banking dan mobile banking

c. Dipotong atau dipungut oleh pemotong atau pemungut pajak

d. Buat kode biling sekaligus membayar pajak UMKM di mesin ATM. Sebagai contoh di ATM Bank BCA, masukkan PIN, pilih transaksi lainnya, pilih pembayaran, tekan MPN/pajak, pilih $\mathrm{PPh}$ Final Bruto Tertentu. Kemudian masukkan 15 digit nomor NPWP, 2 digit bulan, dan 2 digit tahun pajak. Contohnya untuk masa Agustus 2018: 8817208906550000818.

e. Selanjutnya tekan benar. Lalu masukkan jumlah pajak terutang dan pilih benar. Setelah itu, akan muncul pertanyaan apakah Anda ingin membayar, lalu tekan Ya, transaksi selesai. Simpan struk sebagai bukti pembayaran pajak yang sah.(Editorial Forum Pajak Indonesia, 2018)

Tabel 4.. Tehnis Pembayaran Dan Pelaporan Pajak Penghasilan Final

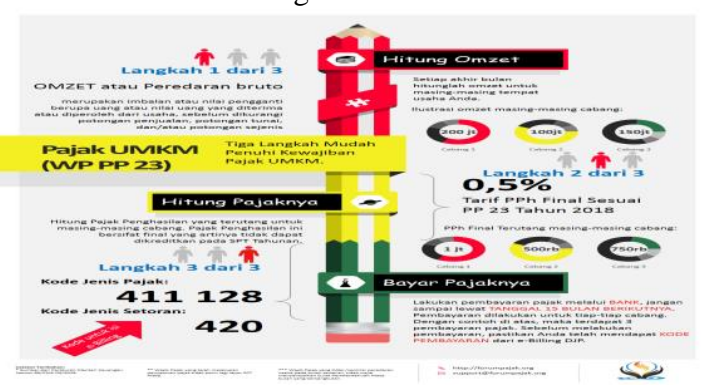

Sumber : https://forumpajak.org/cara-setor-dan-lapor-pphfinal-05/

\section{KESIMPULAN}

1. Peraturan Pemerintah pada prinsipnya merupakan Insentif yang semakin menarik bagi usaha bagi UMKM lama dan UMKM usaha baru agar mau ikut serta berkontribusi membayar pajak. Walaupun peraturan ini membatasi jangka waktu, kemudahan perhitungan dan rendahnya tarif pajak 
diharapkan mampu memikat pembayar pajak baru.

2. Fasilitas ini bersifat selektif dan elektif. Selektif dimaksudkan adalah Wajib Pajak tertentu yang memenuhi kualifikasi/persyaratan tertentu yang boleh memakai fasilitas ini. Elektif artinya Wajib Pajak diberikan pilihan untuk memakai ketentuan ini atau tidak bersedia menggunakannya. Contoh: perusahaan yang baru berkembang, termasuk Startup Company yang masih dalam tahap pengembangan dan/atau belum memungut fee atau penjualan, maupun usaha lain yang masih merugi.

3. Aturan Pelaksanaan dari PP 23 Tahun 2018 ini masih ditunggu, karena masih banyak hal-hal teknis yang belum diatur dan juga masih ada beberapa ketentuan yang belum jelas antara lain:

a. Prosedur dan Persyaratan Pengajuan Surat Keterangan Wajib Pajak yang Dikenakan PPh Final 0,5\% sesuai PP 23 Tahun 2018

b. Perhitungan Angsuran PPh Pasal 25 ketika WP akan beralih ke aturan tarif PPh Pasal 17 (baik karena tidak dipenuhinya syarat sebagai UMKM atau karena berlalunya jangka waktu penggunaan fasilitas).

c. Pihak yang ditetapkan sebagai Pemotong PPh Final (Apakah hanya bendahara saja seperti contoh dalam Penjelasan PP 23 Tahun 2018 atau WP Badan juga dapat melakukan pemotongan).

d. Penegasan dan batasan atas Wajib Pajak Orang Pribadi memiliki keahlian tertentu yang melakukan pekerjaan Bebas namun mempekerjakan orang lain dalam kegiatan usahanya.

4. Berdasarkan UU, Wajib Pajak Badan berbentuk PT, CV, dan Firma tetap harus menyelenggarakan pembukuan sejak awal pendirian usaha tanpa pengecualian, bahkan dengan atau tanpa adanya skema pajak ini. Karena itu, otoritas pajak seyogyanya mampu menjelaskan lebih tegas mengenai kewajiban pembukuan dalam skema perhitungan pajak ini.

5. Bagi Wajib Pajak yang dalam suatu Tahun Pajak mengenakan tarif PPh Pasal 17/Angsuran PPh 25, maka tidak diperkenankan untuk memakai kembali PPh Final sesuai PP 23 Tahun 2018 sekalipun pemakaian PPh Final belum melewati batas jangka waktu yang diperbolehkan.

6. Khusus untuk Wajib Pajak Orang Pribadi (WP OP) yang tergolong pengusaha UMKM diperkenankan untuk menyelenggarakan pencatatan untuk menghitung pajak sesuai norma penghitungan penghasilan neto.

7. Menurut Penulis, pembukuan untuk tujuan perpajakan dapat kita artikan dalam 2 tujuan yaitu:

a. Pembukuan untuk Perhitungan Pajak. Maksudnya adalah terkait dengan kewajiban PP 23 Tahun 2018 ini, maka Wajib Pajak diharapkan mampu rekapitulasi Peredaran Bruto setiap bulan untuk mengetahui jumlah $\mathrm{PPh}$ Final yang harus disetorkan setiap masa pajak.

b. Pembukuan untuk Pelaporan Pajak. Maksudnya adalah terkait dengan kewajiban melaporkan SPT Tahunan, maka setiap Wajib Pajak diwajibkan untuk membuat Laporan Keuangan (Neraca, Laporan Laba/Rugi, Laporan Perubahan Ekuitas) yang menjadi alat pertanggungjawaban bagi jumlah penghasilan terlapor (terutama Laba Ditahan) yang dilaporkan kepada otoritas pajak.

\section{REFERENSI}

Anastasia Diana \& Lilis Setiawati. (2014). Perpajakan, Teori dan Peratueran terkini. Penerbit Andi, Yogyakarta.

Editorial Forum Pajak Indonesia. (2018). Cara Setor dan Lapor PPh Final. Jakarta.

Jakarta Globes. (2018). Gov't Cuts Tax for Small and Medium Enterprises.

Kawan Pajak.com. (2018). Perbandingan PP 46 Tahun 2013 VS PP 23 Tahun 2018. Jakarta.

Mardiasmo. (2011). Perpajakan, Edisi Revisi 2011 (2011th ed.). Yogyakarta: Penerbit Andi.

Murifal, B. (2019). Aspek Pajak Penghasilan Final Pada Sektor Usaha Mikro Kecil dan Menengah (Studi Kasus PT PCT Tangerang). Moneter, 6(1), 33-38.

RI, K. K. (2018). PP 23, TAHUN 2018, TENTANG PAJAK PENGHASILAN ATAS PENGHASILAN DARI USAHA YANG DITERIMA ATAU DIPEROLEH WAJIB PAJAK YANG MEMILIKI PEREDARAN BRUTO TERTENTU. Jakarta.

RI, K. P. (1998). Keputusan Presiden RI no. 99 tahun 1998 tentang: Usaha Mikro, Kecil dan Menengah. In Jakarta.

Rochmat Soemitro. (2012). Perpajakan, Teori dan Tehnis Pemungutan (2012th ed.). Graha Ilmu, Bandung.

Universitas Brawijaya. (2018). Sosialisasi Peraturan Pemerintah No.23 Tahun 2018 Tentang PPh Final UMKM,. Malang.

\section{PROFIL PENULIS}

Badar Murifal SE.,MM, QWP, CFRM, ZC, AT Pendidikan akhir S2 Magister Manajemen , Ipwija Business School. Sertifikat profesi Qualified Wealth Planner. Di UBSI mengajar sejak 2009 s/d saat ini. 